\title{
High-dose inhaled steroids in asthmatics: moderate efficacy gain and suppression of the hypothalamic-pituitary-adrenal (HPA) axis
}

\author{
J. Boe*, P. Bakke**, T. Rødølen+, E. Skovlund+, A. Gulsvik**, \\ for The Research Council of the Norwegian Thoracic Society
}

High-dose inhaled steroids in asthmatics: moderate efficacy gain and suppression of the hypothalamic-pituitary-adrenal (HPA) axis. J. Boe, P. Bakke, T. Rødфlen, E. Skovlund, A. Gulsvik, for The Research Council of the Norwegian Thoracic Society. CERS Journals Ltd 1994.

ABSTRACT: We wanted to evaluate the improvement in efficacy when increasing the daily dose of inhaled steroids and to compare the efficacy, safety, and tolerance of $1.6 \mathrm{mg}$ beclomethasone dipropionate (BDP) with that of $2.0 \mathrm{mg}$ fluticasone propionate (FP).

The study was a randomized, double-blind, 3 month, multicentre study. One hundred and thirty four asthmatics currently using inhaled steroids $(0.4-1.6 \mathrm{mg}$ BDP or budesonide (BUD)) were stratified according to pretrial daily steroid use. Within each stratum they were randomized to either $1.6 \mathrm{mg}$ BDP or $2.0 \mathrm{mg}$ FP.

A significant increase in the primary efficacy variables, i.e. mean morning and evening peak expiratory flow (PEF) (approximately $20 \mathrm{l} \cdot \mathrm{min}^{-1}$ ) during the treatment period, was found for both treatments. No significant differences between the drugs were revealed for these primary or any other secondary efficacy variables (use of beta ${ }_{2}$-agonists, symptom scores, and PEF, forced vital capacity $(F V C)$, forced expiratory volume in one second $\left(\mathrm{FEV}_{1}\right)$ recorded at the clinical visits). However, significant differences between treatments occurred regarding decrease of serum cortisol and adrenocorticotropic hormone.

We conclude that, although both treatments gave statistically significant increases in efficacy parameters when compared with baseline, the increases were so small that they can be regarded as being clinically unimportant. Daily doses of BDP, $1.6 \mathrm{mg}$, and FP, $2.0 \mathrm{mg}$, had comparable effects on lung function. A suppression of the hypothalamic pituitary adrenal (HPA) axis was only found with a daily dose of $2 \mathrm{mg}$ FP.

Eur Respir J., 1994, 7, 2179-2184.
*Dept of Thoracic Medicine, National Hospital, Rikshospitalet, University of Oslo, Oslo, Norway. **Dept of Thoracic Medicine, Haukeland Hospital, University of Bergen, Bergen, Norway. ${ }^{+}$Granheim Lung Hospital, Follebu, Norway. ${ }^{++}$Dept of Mathematics, University of Oslo, Oslo, Norway.

Correspondence: J. Boe

Dept of Thoracic Medicine

Rikshospitalet

0027 Oslo

Norway

\section{Keywords: Asthma}

beclomethasone dipropionate

drug treatment

fluticasone propionate

inhaled corticosteroids

Received: February 221994

Accepted after revision August 81994
There is now extensive evidence that inhaled corticosteroids are effective in the management of asthma [1]. Conflicting results exist, however, as to whether they exhibit a dose-response relationship regarding their antiasthma effects [2]. In a former study, no statistically significant differences between beclomethasone (BDP) and budesonide (BUD) in the dose range $400-1000 \mu \mathrm{g}$ were found [3]. In patients receiving 400 $\mu \mathrm{g}$ daily, doubling the dose did not produce clinical benefits [3]. It might be argued that additional efficacy could be obtained by increasing the dose of BUD from 400 to $1,600 \mu \mathrm{g}$ [4]. The effects of doses of inhaled corticosteroids higher than 2,000 $\mu \mathrm{g}$ are virtually un-known.

Higher doses of inhaled corticosteroids increase the risk of suppression of the endogenous cortisol secretion [2] and of local side-effects. Consequently, inhaled corticosteroids with more potent topical effects and less systemic effects than those available today are needed. Fluticasone propionate (FP) is a new synthetic glucocorticoid with high topical potency in humans compared to BDP [5]. The drug also has a poor gastrointestinal absorption and an extensive hepatic extraction ratio, giving an oral bioavailability of less than $1 \%[6]$.

In 1990, The Research Council of the Norwegian Thoracic Society set out to start a clinical study in order to evaluate the effects of very high doses of inhaled corticosteroids in asthma. Initially, we planned to compare the highest dose of BDP recommended in Norway, 1,600 $\mu \mathrm{g}$, with 4,000 $\mu \mathrm{g}$ BDP. Due to the assumed better efficacy/side-effect ratio with FP we decided to use this drug instead of BDP as our very high-dose alternative. This decision was based mainly on studies available at that time, indicating a favourable potency ratio for FP versus BDP [7]. We therefore chose a dose of 2,000 $\mu \mathrm{g}$ FP as our very high-dose alternative.

Thus, the objectives of the present study were twofold: 1) to evaluate the improvement in efficacy that could be obtained when increasing the daily dose of 
inhaled corticosteroids up to $1.6 \mathrm{mg}$ BDP or $2.0 \mathrm{mg} \mathrm{FP}$; and 2) to compare the efficacy, safety, and tolerance of a daily dose of $1.6 \mathrm{mg}$ BDP with that of $2.0 \mathrm{mg}$ FP in patients currently treated with inhaled steroids.

\section{Material and methods}

\section{Study design}

The study was a randomized, double-blind, multicentre trial. The patients were stratified according to pretrial daily steroid use $(0.4-0.8 \mathrm{mg},>0.8-1.6 \mathrm{mg}$, or $>1.6-2.0 \mathrm{mg}$ BDP or BUD daily). Within each stratum, they were randomized to receive either 1.6 BDP or $2.0 \mathrm{mg}$ FP daily for 3 months. During this period, they were seen by a physician every $2-4$ weeks. The patients then returned to their pretrial inhaled steroid medication and were followed for two weeks after cessation of study drugs.

BDP $0.8 \mathrm{mg} b . d$. and FP $1.0 \mathrm{mg} b . d$. were administered through an 8 -place Rotadisk $\left(0.4\right.$ and $0.5 \mathrm{mg} \cdot$ blister $^{-1}$, respectively) with the aid of a Diskhaler.

From the start of the run-in period until the last visit, the patients had access to a bronchodilator which they were told to use only on demand. All other antiasthma medication was to be kept unchanged during the study. Each morning and evening throughout the study, the patients recorded the overall symptom score (table 1) during the night and day, and the number of times the bronchodilator had been used. Every morning and evening the patients also performed peak expiratory flow measurements (PEF) with a mini-Wright peak flowmeter, recording the highest of three measurements. At each visit, the patients' diary cards were checked for completeness by a physician.

At each visit, measurements of PEF, forced expiratory volume in one second $\left(\mathrm{FEV}_{1}\right)$ and forced vital capacity (FVC) were performed. For each variable, the highest of three measurements was recorded. The patients were encouraged not to use their bronchodilator for $4 \mathrm{~h}$ prior to the examination.

The hypothalamic-pituitary-adrenal (HPA) function was tested by measuring serum cortisol and plasma adrenocorticotropic hormone (ACTH) at weeks 0,4 and 12 of the treatment period, and at follow-up. At all visits, the laboratory and respiratory physiological measurements took place between 8 and 10 a.m. Serum cortisol was measured by a radioimmunoassay (Farmos, Orion comp., Turku, Finland). The intra-assay coefficient of variation was $4.2-7.9 \%$ at levels ranging $20-2,000 \mathrm{nmol} \cdot l^{-1}$, and the interassay coefficient of variation was 5.0, 5.8 and $5.9 \%$ at dose levels 259, 522 and 1,299 $\mathrm{nmol} \cdot l^{-1}$, respectively. Plasma ACTH was measured by a chemiluminoimmunoassay (Henning $\mathrm{GmbH}$, Berlin, Germany). The intra-assay coefficient of variation was $2.2-6.8 \%$ at levels ranging 5-500 $\mathrm{ng} \cdot \mathrm{l}^{-1}$, and the interassay coefficient of variation was 20.2 and $20.0 \%$ at dose levels 31 and $314 \mathrm{ng} \cdot l^{-1}$, respectively. The measurements were performed at the Hormone Laboratory, Aker University Hospital, Oslo.

Oropharyngeal examination was carried out, and if clinically indicated, swabs were taken for assessment of candidiasis. Side-effects were actively asked for by the physician, and all side-effects were recorded.

An asthma exacerbation was defined as a PEF recording less than $75 \%$ of the mean values during the run-in period. In case of an exacerbation, prednisolone was given at a dose of $30 \mathrm{mg}$ daily for one week. No outcome variables recorded within 4 weeks following an exacerbation were used in an analysis of outcome. If the prednisolone treatment had to be continued for more than a week or another treatment except antibiotics for respiratory infections had to be administered, the patient was withdrawn from the study. Dosage regimens and dates of all additional medications were recorded.

\section{Patients}

Subjects aged 18 yrs or more with a clinical diagnosis of asthma were eligible to enter the study if they had been receiving $0.4-2.0 \mathrm{mg}$ of BDP or BUD at least 4 weeks prior to the study. Despite this treatment, the patients had to show some evidence of lack of good asthma control. Thus, at the end of the 2 week run-in period, the patients had to fulfil at least two of the following criteria: 1) $\mathrm{FEV}_{1}<80 \%$ of predicted [8] at pretrial or first trial visit; 2) mean morning PEF during last 7 days of run-in period $<80 \%$ of predicted [8]; 3 ) diurnal variation in PEF of at least $\pm 20 \%$ on a minimum of four of the last seven days of the run-in

Table 1. - Assessing overall symptoms twice daily in the morning (symptoms from evening to morning) and in the evening (symptoms from morning to evening) with the aid of symptom scores

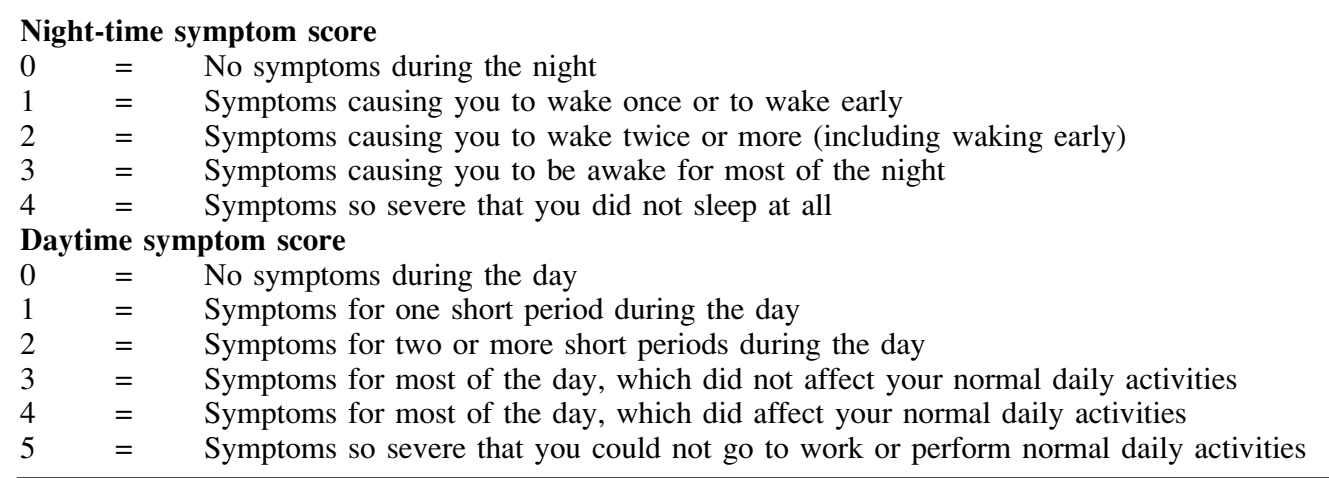


period; 4) asthma symptoms during a minimum of four $24 \mathrm{~h}$ periods in the last 7 days of the run-in period. All but four of the patients fulfilled criterion 4 in combination with at least one other criterion. In three patients, the combination of inclusion criteria was 1 and 2, 1 and 3, and 1, 2 and 3, respectively. The fourth patient did not fulfil any of the inclusion criteria, and was consequently excluded from evaluation. Patients were further excluded if they had used oral corticosteroids during the last 4 weeks preceding the study.

The study was conducted according to Nordic Guidelines for Good Clinical Trial Practice [9], and was approved by the Regional Ethics Committee in Oslo. Written informed consent was obtained before the patient was included in the study.

\section{Statistical analysis}

To estimate the sample size needed, the following assumptions were made. A difference in PEF between the two treatments of $30 \mathrm{l} \cdot \mathrm{min}^{-1}$ was considered clinically relevant. The standard deviation of the change from baseline was expected to be about twice the size of the clinically relevant difference. To obtain a two-sided significance level of 0.05 and a power of $0.80,65$ patients were needed in each treatment group.

Statistical analyses were performed using the program systems SAS and BLSS [10]. The primary efficacy variables used were the daily morning and evening PEF. They were analysed separately by estimating a regression line based on the diary card data over the 12 weeks treatment period for each patient. The slopes of these individual regression lines were used as the dependent variable in a multiple linear regression, with treatment and stratum as independent variables.

\section{Results}

A total of 134 patients entered the study, of whom 71 received FP and $63 \mathrm{BDP}$. The two groups were comparable regarding age, height, weight, smoking habits, and lung function (table 2). The number of patients

Table 2. - Patient characteristics for the total study population

\begin{tabular}{lcc}
\hline & FP & BDP \\
\hline Patients n & 71 & 63 \\
Sex M/F & $39 / 32$ & $41 / 22$ \\
Age yrs* & $51(20-74)$ & $51(27-75)$ \\
Height cm* & $172(156-190)$ & $172(160-187)$ \\
Weight kg* & $74(42-110)$ & $72(50-103)$ \\
Smokers n & 27 & 19 \\
FEV $l^{* *}$ & $2.04 \pm 0.66$ & $2.10 \pm 0.93$ \\
FVC $l^{* *}$ & $3.28 \pm 0.81$ & $3.36+1.04$ \\
PEF $l \cdot$ min $^{-1 * *}$ & $376 \pm 128$ & $372 \pm 128$ \\
\hline
\end{tabular}

*: data are presented as mean, and range in parenthesis; **: data are presented as mean \pm SD. FP: fluticasone propionate; BDP: beclomethasone dipropionate; $\mathrm{M}$ : male; F: female; $\mathrm{FEV}_{1}$ : forced expiratory volume in one second; FVC: forced vital capacity; PEF: peak expiratory flow; n: number, in was 46,80 , and 8 in each stratum according to pretrial daily steriod use, respectively. Two different populations were analysed; the total population of all 134 individuals and the efficacy population of 116 patients. Reasons for not including patients in the efficacy population are listed in table 3 . Twelve patients withdrew from the study prematurely (table 4). Data for these patients have been included in the analysis up to the time of the withdrawal.

A significant increase in PEF $(\mathrm{p}<0.05)$ over the treatment period was found both for morning and evening PEF (table 5). No statistically significant differences between treatments or strata were found. Figure 1 shows mean morning and evening PEF during the treatment period.

Table 6 shows the estimated mean use of beta $_{2}-$ agonists and mean symptom score. There were no significant differences between treatment groups. Both symptom scores and use of beta $a_{2}$-agonists were significantly reduced during the study.

The mean PEF, FEV F $_{1}$ and FVC recorded at the clin-

Table 3. - Number of events and reasons for not being included in the efficacy population

\begin{tabular}{lccc}
\hline & FP & BDP & Total \\
\hline Inclusion criteria violated & 0 & 2 & 2 \\
Asthma exacerbations during treatment & 3 & 8 & 11 \\
Asthma exacerbations during follow-up & 1 & 2 & 3 \\
Noncompliant & 3 & 2 & 5 \\
\hline Total number of events & 7 & 14 & 21 \\
\hline
\end{tabular}

FP: fluticasone propionate; BDP: beclomethasone dipropionate. Some patients have more than one event.

Table 4. - Number of patients and reasons for withdrawal during the study

\begin{tabular}{lccc}
\hline & FP & BDP & Total \\
\hline Adverse event & 6 & 1 & 7 \\
Failed to return & 1 & 2 & 3 \\
Noncompliant & 1 & 0 & 1 \\
Wanted to withdraw & 1 & 0 & 1 \\
\hline Total & 9 & 3 & 12 \\
\hline
\end{tabular}

FP: fluticasone propionate; BDP: beclomethasone dipropionate.

Table 5. - Estimated increase in PEF $\left(l \cdot \mathrm{min}^{-1}\right)$ per day over the 12 week treatment period

\begin{tabular}{|c|c|c|}
\hline & FP & BDP \\
\hline \multicolumn{3}{|c|}{ Total population } \\
\hline Subject $\mathrm{n}$ & 71 & 63 \\
\hline Morning PEF & $0.147(0.106)$ & $0.276(0.113)$ \\
\hline Evening PEF & $0.299(0.143)$ & $0.340(0.108)$ \\
\hline \multicolumn{3}{|c|}{ Efficacy population } \\
\hline Subject $\mathrm{n}$ & 65 & 51 \\
\hline Morning PEF & $0.125(0.108)$ & $0.299(0.118)$ \\
\hline Evening PEF & $0.184(0.118)$ & $0.262(0.143)$ \\
\hline
\end{tabular}

Data are presented as mean, and SEM in parenthesis. PEF: peak expiratory flow $\left(l \cdot \mathrm{min}^{-1}\right)$; FP: fluticasone propionate; BDP: beclomethasone dipropionate; n: number. 


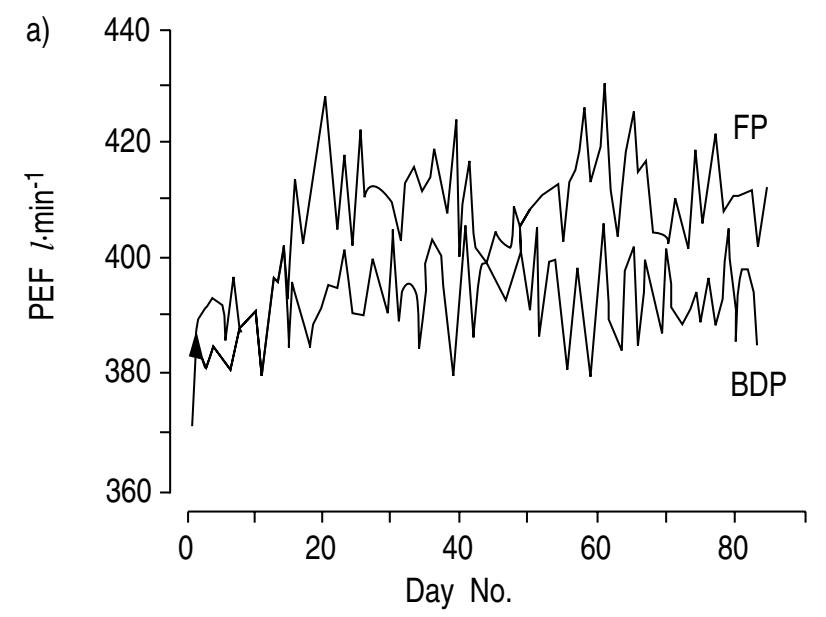

ic visits are shown in table 7. All changes from baseline are consistently statistically significant at $\mathrm{p}<0.05$. There were no statistically significant differences between treatments or strata. Analysis of the data from the efficacy population gave almost identical results.

Table 8 shows mean change from baseline values for serum cortisol and plasma ACTH in each treatment group at three different visits for the total population. Analysis of covariance with serum cortisol and ACTH as dependent variables (in two separate analyses), and treatment, stratum, centre, and the baseline reading as covariates showed no significant effect of stratum or centre. In the analysis of serum cortisol, we controlled for the baseline value and found significant differences between FP and BDP $(p<0.001)$ at 4 and 12 weeks, but no significant difference at the follow-up visit (14 weeks). The corresponding analysis of ACTH showed a significant difference between treatments at 4 weeks $(\mathrm{p}=0.011)$ and "borderline significance" $(\mathrm{p}=0.064)$ at 12 weeks. At the

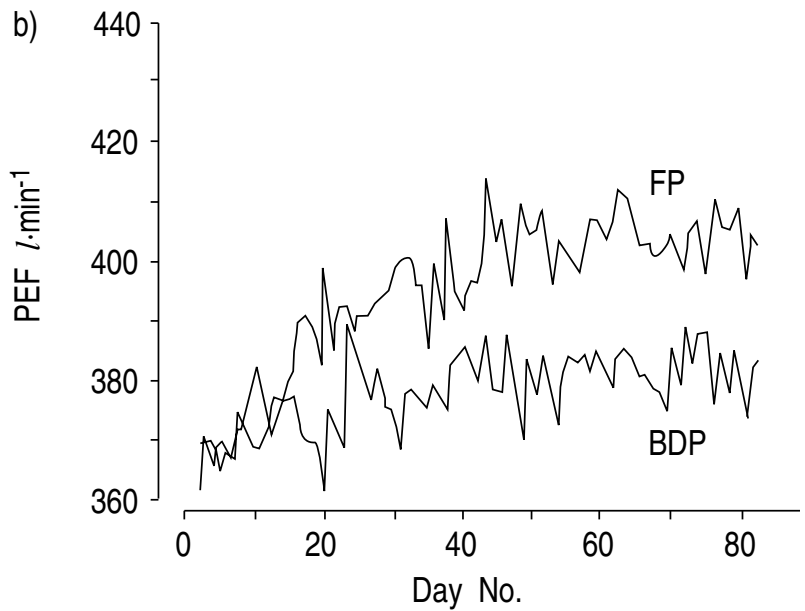

Fig. 1. - a) Mean morning; and b) evening peak expiratory flow (PEF) in each treatment group during the treatment period. FP: fluticasone propionate; BDP: beclomethasone dipropionate.

Table 6. - Baseline values and symptom score and use of beta $_{2}$-agonist (puffs per day or night) over the 12 week treatment period

\begin{tabular}{lcccc}
\hline & \multicolumn{2}{c}{$\begin{array}{c}\text { Symptom } \\
\text { FP }\end{array}$} & BDP & \multicolumn{2}{c}{ Use of beta $_{2}$-agonist } \\
& & & & \\
& & & & \\
Daily & 1.70 & 1.94 & 2.75 & 2.92 \\
Baseline & $(0.11)$ & $(0.11)$ & $(0.24)$ & $(0.24)$ \\
Treatment & 1.35 & 1.60 & 2.24 & 2.35 \\
& $(0.13)$ & $(0.12)$ & $(0.24)$ & $(0.25)$ \\
Nightly & & & & \\
Baseline & 0.77 & 0.85 & 0.77 & 0.76 \\
& $(0.08)$ & $(0.08)$ & $(0.12)$ & $(0.11)$ \\
Treatment & 0.62 & 0.65 & 0.73 & 0.51 \\
& $(0.08)$ & $(0.08)$ & $(0.14)$ & $(0.09)$ \\
\hline
\end{tabular}

Data are presented as mean and SEM in parenthesis. FP: fluticasone propionate; BDP: beclomethasone dipropionate. ferent.

Both drugs were well-tolerated. The most common side-effects were candidiasis, sore throat, and hoarseness due to local effects of the inhaled steroids. The number

Table 8. - Mean (SEM) change from baseline for serum cortisol and ACTH in the total study population

\begin{tabular}{lcccc}
\hline & \multicolumn{2}{c}{$\Delta$ Serum cortisol nmol $\cdot l^{-1}$} & \multicolumn{2}{c}{$\Delta$ ACTH $\mathrm{ng} \cdot l^{-1}$} \\
Week & FP & BDP & FP & BDP \\
\hline 4 & -132.2 & 13.0 & -11.1 & 2.9 \\
& $(22.1)$ & $(18.6)$ & $(2.2)$ & $(5.0)$ \\
12 & -133.5 & 40.4 & -10.6 & -2.0 \\
& $(26.5)$ & $(26.9)$ & $(3.2)$ & $(2.6)$ \\
14 & -11.9 & 44.2 & 0.04 & -0.26 \\
& $(23.6)$ & $(18.2)$ & $(3.4)$ & $(3.1)$ \\
\hline
\end{tabular}

ACTH: adrenocorticotropic hormone; FP: fluticasone propionate; BDP: beclomethasone dipropionate.

Table 9. - Number of patients reporting side-effects during the different treatment periods; some patients had more than one side-effect

\begin{tabular}{lcc}
\hline & FP & BDP \\
& $\mathrm{n}$ & $\mathrm{n}$ \\
\hline Candidiasis & 22 & 19 \\
Sore throat & 20 & 9 \\
Hoarseness & 10 & 3 \\
Lower airways infection/pneumonia & 10 & 6 \\
Common cold/influenza/fever & 19 & 24 \\
Headache & 11 & 5 \\
Musculoskeletal disorders & 9 & 16 \\
Gastrointestinal disorders & 9 & 12 \\
Increased weight/swollen face & 3 & 0 \\
\hline
\end{tabular}

FP: fluticasone propionate; BDP: beclomethasone dipropionate.

Table 7. - Pulmonary function data $\left(\mathrm{PEF}, \mathrm{FEV}_{1}, \mathrm{FVC}\right)$ recorded at the clinic visits

\begin{tabular}{llccccc}
\hline & \multicolumn{2}{c}{ PEF } & $l \cdot \mathrm{min}^{-1}$ & \multicolumn{2}{c}{ FEV $_{1} l$} & \multicolumn{2}{c}{ FVC $l$} \\
& FP & BDP & FP & BDP & FP & BDP \\
\hline Baseline & $376.5(18.5)^{*}$ & $371.6(19.2)^{*}$ & $2.04(0.10)^{*}$ & $2.10(0.14)^{*}$ & $3.28(0.12)^{*}$ & $3.36(0.16)^{*}$ \\
Week 2 & $397.6(18.9)$ & $391.7(20.0)$ & $2.17(0.10)$ & $2.17(0.12)$ & $3.44(0.12)$ & $3.52(0.15)$ \\
Week 4 & $413.4(21.1)$ & $394.1(20.4)$ & $2.22(0.10)$ & $2.19(0.13)$ & $3.54(0.12)$ & $3.54(0.16)$ \\
Week 12 & $408.1(21.9)$ & $399.0(19.1)$ & $2.23(0.11)$ & $2.16(0.13)$ & $3.54(0.13)$ & $3.53(0.16)$ \\
\hline
\end{tabular}

Data are presented as mean, and SEM in parenthesis. For abbreviations see legend to table 2. *: p<0.05 vs treatment period values. 
of side-effects were similar in both groups and no lifethreatening side-effects or death occurred during the study (table 9).

\section{Discussion}

The aim of our study was primarily to evaluate the improvement in efficacy when increasing the dose of inhaled steroids, and secondarily to compare the effects of a "very high" dose of corticosteroids, FP $2.0 \mathrm{mg}$, with the highest usually recommended dose of BDP, $1.6 \mathrm{mg}$. We found that the two treatment regimens had comparable effects on lung function in terms of $\mathrm{FEV}_{1}$, FVC and PEF, as well as symptom score. Both treatments gave an increase in PEF of approximately $20 l \cdot \mathrm{min}^{-1}$ during the treatment period, which is lower than we regard as clinically important, although statistically significant. This increase may be due to "regression to the mean", and also an effect of being included in a clinical trial ("Hawthorne effect") [11]. Therefore, generally speaking, we were unable to demonstrate a clinically important therapeutic gain in using very high doses of inhaled steroids.

In our study, we showed FP $2.0 \mathrm{mg}$ and BDP $1.6 \mathrm{mg}$ to have equal efficacy. In two former studies, we were also unable to show significant differences regarding efficacy when comparing BDP $1 \mathrm{mg}$ and BUD $0.8 \mathrm{mg}$ [3], or $200 \mu \mathrm{g}$ BUD and $400 \mu \mathrm{g}$ BUD, daily [12]. These findings are contradictory to recent studies comparing BDP in daily doses of $0.4-2.0 \mathrm{mg}$ to FP in daily doses of $0.2-1.5 \mathrm{mg}$ [13-17], which showed FP to be as effective as or more effective than BDP in controlling asthma, even when administered at a lower dose. The reason for this discrepancy is unclear, but it may be that a therapeutic gain when increasing the dose of an inhaled steroid can only be expected in mild asthmatics on low dose therapy. When high dose therapy is recommended in such patients, different inhaled steroids seem to have equal efficacy.

A further explanation for our inability to show differences in effect between FP and BDP in the dose range used may be that we had reached the plateau of the dose-response curve. Whether or not a dose-response pattern really exists for steroids can be debated [2, 3, 18], although there are studies indicating that such a relationship exists at least with inhaled steroids in low doses [16, 18, 19].

There may even be other explanations for our inability to find a difference in effect between the two drugs. It could be argued that the number of patients included in our study was too small to allow us to detect differences between the drugs. Based on the study results, the standard deviation of the change from baseline was estimated as approximately $80 l \cdot \mathrm{min}^{-1}$. Hence, the inclusion of 134 patients resulted in a lower power than planned. It is reduced from 0.8 to approximately 0.65 , but we still believe our results to be clinically valid (as the p-values are indeed far from the 5\% level). Furthermore, the present trial period may have been too short to reflect any difference between the treatment regimens. How- ever, our data did not indicate that a longer trial period would have revealed any differences. Finally, when comparing the results of different studies it should be kept in mind that patient characteristics may vary between studies.

We evaluated the function of the HPA axis in terms of morning serum cortisol and plasma ACTH. Most studies examining the effect of inhaled corticosteroids on the hypothalamic-pituitary-adrenal axis have used morning serum cortisol level, or included the short tetracosactrin test or $24 \mathrm{~h}$ urinary free cortisol [20]. Although a single plasma cortisol level is regarded as the least sensitive test [18], we believe that a combination of morning cortisol with ACTH measurements allows us to study effects of the inhaled drugs on the HPA axis.

In our study we observed that FP, $2.0 \mathrm{mg} \cdot$ day $^{-1}$, suppressed the hypothalamic-pituitary-adrenal axis, whilst BDP, $1.6 \mathrm{mg} \cdot$ day $^{-1}$, did not. Recent studies of asthmatics taking FP in daily doses varying between $0.2-1.5 \mathrm{mg}$ have not observed any suppression of the hypothalamicpituitary-adrenal axis [13-16]. This has been explained by the low oral bioavailability of FP compared to BDP and BUD [6, 18]. The fact that we observed an effect on the HPA axis of FP $2.0 \mathrm{mg} \cdot \mathrm{day}^{-1}$, whilst such an effect has not been observed up to $1.5 \mathrm{mg} \cdot$ daily $^{-1}$, does not necessarily indicate that there is a threshold level between 1.5 and $2.0 \mathrm{mg}$ daily. It can be speculated, however, that inhaled FP in high doses may be absorbed systemically from the airways.

In conclusion, our study showed that FP, $2.0 \mathrm{mg}$ daily, and BDP, $1.6 \mathrm{mg}$ daily, have comparable effects on lung function. A suppression of the HPA axis occurred with FP $2.0 \mathrm{mg}$ daily.

Acknowledgement: The authors thank Glaxo Norway, who provided us with clinical supplies and helped us monitor the study. Participating physicians: P. Bakke, Bergen; E. Bjørnstad, Oslo; Ø. Bjørtuft, Oslo; J. Boe, Oslo; N.P. Boye, Oslo; R. Dahle, Fredrikstad; I. Ellingsen, Bergen; E. Gløersen, Akershus; A. Gulsvik, Bergen; A. Gyltnes, Troms $\varnothing$; J.H. Holmboe, Bergen; S.Ø. Jørstad, Fredrikstad; B. Jakobsen, Molde; R. Kibsgaard, Levanger; F. Kjelsberg, Akershus; T. Kristiansen, Oslo; T. Naustdal, Levanger; S. Riis, Fredrikstad; N. Ringdal, Molde; T. Rødølen, Follebu; R. Walstad, Trondheim; F. Wammer, Trondheim; U. Aasebø, Tromsø.

\section{References}

1. British Thoracic Society. Guidelines for management of asthma in adults. I. Chronic persistent asthma. $\mathrm{Br}$ Med J 1990; 301: 651-653.

2. Geddes D. Inhaled corticosteroids: benefits and risks. Thorax 1992; 47: 404-407.

3. Boe J, Rosenhall L, Alton M, et al. Comparison of doseresponse effects of inhaled beclomethasone dipropionate and budesonide in the management of asthma. Allergy 1989; 44: 349-355.

4. Tukiainen P, Lahdensuo A. Effect of inhaled budesonide on severe steroid-dependent asthma. Eur J Respir Dis 1987; 70: 239-244.

5. Phillips G. Structure-activity relationships of topically active steroids: the selection of fluticasone propionate. Respir Med 1990; 84 (Suppl. A): 19-23.

6. Harding S. The human pharmacology of fluticasone 
propionate. Respir Med 1990; 84 (Suppl. A): 25-29.

7. Bauer K, Bantje TA, Sips AP, et al. The effect of inhaled fluticasone propionate (FP), a new potent corticosteroid in severe asthma. Eur Respir J 1988; 1 (Suppl. 2): 201s.

8. Quanjer PH, Dalhuijsen A, van Zomeren B. Summary equations for reference values. Bull Eur Physiopathol Respir 1983; 19 (Suppl. 5): 45-51.

9. Good Clinical Trial Practice. Nordic Guidelines. Nordic Council on Medicines, Uppsala, 1989.

10. Abrahams DM, Rizzardi F. BLSS. The Berkeley Interactive Statistical System. New York, WW Norton, 1988.

11. Parsons HM. What happened at Hawthorne? Science 1974; 183: 922-932.

12. Lorentzson S, Boe J, Eriksson G, Persson G. Use of inhaled corticosteroids in patients with mild asthma. Thorax 1990; 45: 733-735.

13. Fabbri L, Burge P, Croonenborgh L, et al. Comparison of fluticasone propionate with beclomethasone dipropionate in moderate to severe asthma treated for one year. Thorax 1993; 48: 817-823.

14. Barnes NC, Marone G, Di Maria GU, et al. A comparison of fluticasone propionate, $1 \mathrm{mg}$ daily, with beclomethasone dipropionate, $2 \mathrm{mg}$ daily, in the treatment of severe asthma. Eur Respir J 1993; 6: 877-884.

15. Gustafsson P, Tsanakas J, Gold M, et al. Comparison of the efficacy and safety of inhaled fluticasone propionate $200 \mu \mathrm{g} \cdot \mathrm{day}^{-1}$ with inhaled beclomethasone dipropionate $400 \mu \mathrm{g} \cdot \mathrm{day}^{-1}$ in mild and moderate asthma. Arch Dis Child 1993; 69: 206-211.

16. Dahl R, Lundbäck B, Malo J-L, et al. A dose-ranging study of fluticasone propionate in adult patients with moderate asthma. Chest 1993; 104: 1352-1358.

17. Lundbäck B, Alexander M, Day J, et al. Evaluation of fluticasone propionate $\left(500 \mu \mathrm{g} \cdot \mathrm{day}^{-1}\right)$ administered either as dry powder via a Diskhaler inhaler or pressurized inhaler and compared with beclomethasone dipropionate $\left(1,000 \mu \mathrm{g} \cdot \mathrm{day}^{-1}\right)$ administered by pressurized inhaler. Respir Med 1993; 87: 609-620.

18. Barnes PJ, Pederssen S. Efficacy and safety of inhaled corticosteroids in asthma. Am Rev Respir Dis 1993; 148: S1-S26.

19. Brompton Hospital and Medical Research Council. Double-blind trial comparing two dosage schedules of beclomethasone dipropionate aerosol with a placebo in chronic bronchial asthma. J Dis Chest 1979; 73: 121132.

20. Brown PH, Blundell G, Greening AP, Crompton GK. Screening for hypothalamo-pituitary-adrenal axis suppression in asthmatics taking high dose inhaled corticosteroids. Respir Med 1991; 85: 511-516. 